\title{
Sequence Variations Among 17 New Radish Isolates of Turnip mosaic virus Showing Differential Pathogenicity and Infectivity in Nicotiana benthamiana, Brassica rapa, and Raphanus sativus
}

\author{
Junsu Gong, ${ }^{1}$ Hye-Kyoung Ju, ${ }^{1}$ Ik-Hyun Kim, ${ }^{1}$ Eun-Young Seo, ${ }^{1}$ In-Sook Cho, ${ }^{2}$ Wen-Xing Hu, ${ }^{1}$ Jae-Yeong Han, ${ }^{1}$ Jung-Kyu \\ Kim, ${ }^{1}$ Su Ryun Choi, ${ }^{3}$ Young Pyo Lim, ${ }^{3}$ John Hammond,,$+\dagger$ and Hyoun-Sub Lim ${ }^{1, \dagger}$ \\ ${ }^{1}$ Department of Applied Biology, College of Agriculture and Life Sciences, Chungnam National University, Daejeon 305-764, Korea; ${ }^{2}$ Rural \\ Development Administration, National Institute of Horticultural and Herbal Science, 100 Jeollabuk-do, Korea; ${ }^{3}$ Department of Horticulture, \\ College of Agriculture and Life Sciences, Chungnam National University, Daejeon 305-764, Korea; and ${ }^{4}$ Floral and Nursery Plants Research \\ Unit, U.S. National Arboretum, U.S. Department of Agriculture Agricultural Research Service, Beltsville, MD 20705, U.S.A. \\ Accepted for publication 3 January 2019.
}

\begin{abstract}
Infectious clones were generated from 17 new Korean radish isolates of Turnip mosaic virus (TuMV). Phylogenetic analysis indicated that all new isolates, and three previously characterized Korean radish isolates, belong to the basal-BR group (indicating that the pathotype can infect both Brassica and Raphanus spp.). Pairwise analysis revealed genomic nucleotide and polyprotein amino acid identities of $>87.9$ and $>95.7 \%$, respectively. Five clones (HJY1, HJY2, KIH2, BE, and prior isolate R007) had lower sequence identities than other isolates and produced mild symptoms in Nicotiana benthamiana. These isolates formed three distinct sequence classes (HJY1/HJY2/R007, KIH2, and BE), and several

induced systemic necrosis in $N$. benthamiana. Four mild isolates formed a phylogenetic subclade separate from another subclade including all of the necrosis-inducing isolates plus mild isolate KIH2. Symptom severity in radish and Chinese cabbage genotypes was not correlated with pathogenicity in $N$. benthamiana; indeed, Chinese cabbage cultivar Norang was not infected by any isolate, whereas Chinese cabbage cultivar Chusarang was uniformly susceptible. Four isolates were unable to infect radish cultivar Iljin, but no specific amino acid residues were correlated with avirulence. These results may lead to the identification of new resistance genes against TuMV.
\end{abstract} differential amino acid residues (in $\mathrm{P} 1, \mathrm{P} 3,6 \mathrm{~K} 2$, and $\mathrm{VPg}$ ) were present only in mild isolates HJY1, HJY2, and R007. The remaining isolates all
Keywords: cDNA infectious clone, full-length, Turnip mosaic virus.
Turnip mosaic virus (TuMV) belongs to the genus Potyvirus in the family Potyviridae, the largest genus and family among plant viruses with RNA genomes (Revers and Garcia 2015; Shukla et al. 1994). TuMV infects many plant species, mostly from the Brassicaceae, and only Cucumber mosaic virus is more important in infecting field-grown vegetables worldwide (Tan et al. 2005; Tomlinson 1987; Walsh and Jenner 2002). TuMV is the most significant virus infecting agronomic and ornamental species of the Brassicaceae worldwide, especially cultivated brassicas in East Asia (Tomimura et al. 2003). Although many potyviruses have narrow host ranges, TuMV infects more than 318 plant species in 156 genera of 43 families, including many important crops and weed plants, and is transmitted nonpersistently by at least 89 aphid species (Sánchez et al. 2003).

The TuMV genome is a single-stranded, positive-sense RNA of about $9.8 \mathrm{~kb}$, encoding a single open reading frame, encapsidated in flexuous filamentous particles 700 to $750 \mathrm{~nm}$ long (Walsh and Jenner 2002). The potyvirus genome is linked covalently at its $5^{\prime}$

†Corresponding authors: H.-S. Lim; hyounlim@cnu.ac.kr, and J. Hammond; john.hammond@ars.usda.gov

Funding: This work was supported by the Korea Institute of Planning and Evaluation for Technology in Food, Agriculture, Forestry and Fisheries through the Ministry of Agriculture, Food and Rural Affairs Golden Seed Project (grant 213006-05-1-SBL20)

J. Gong, H.-K. Ju, and I.-H. Kim contributed equally to this work.

*The $e$-Xtra logo stands for "electronic extra" and indicates that three supplementary figures and four supplementary tables are published online.

The author(s) declare no conflict of interest.

(c) 2019 The American Phytopathological Society end to a virus-encoded genome-linked protein (VPg) and has a $3^{\prime}$ polyadenylate tail (Dougherty et al. 1988). The genome is translated into a single polyprotein that is cleaved by three virus-encoded proteases into 10 mature proteins, respectively, as follows: P1, Helper component protease (HC-Pro), P3, 6K 1 , cylindrical inclusion $(\mathrm{CI}), 6 \mathrm{~K}_{2}, \mathrm{VPg}$, nuclear inclusion protein a protease (NIaPro), nuclear inclusion protein $\mathrm{b}(\mathrm{NIb}$; RdRp), and the coat protein (CP) (Walsh and Jenner 2002). An additional coding region, PIPO, occurs within the sequence of the $\mathrm{P} 3$ gene as a result of polymerase slippage resulting in a frameshift into the +2 reading frame (Chung et al. 2008; Olspert et al. 2015; Rodamilans et al. 2015; White 2015).

Because TuMV has a broad host range and is distributed worldwide, there is significant interest in the evolution of TuMV isolates with differential host ranges. Two major groups have been identified based on host type: [B]-host-type isolates mainly infect species of Brassica but not radish (Raphanus sativus), whereas [BR]-host-type isolates infect both Brassica and Raphanus; [(B)]host-type isolates are able to infect Brassica occasionally but latently and do not infect Raphanus, whereas [B(R)]-host-type isolates infect many Brassica lines, causing systemic mosaic, and occasionally infect Raphanus (Nguyen et al. 2013a; Ohshima et al. 2002). Additional, largely parallel, groupings are based on phylogenetic analysis (Tan et al. 2005). The phylogenetic groups are the basal-B, basal-BR, Asian-BR, and world-B lineages (Ohshima et al. 2002; Tan et al. 2004; Tomimura et al. 2003). The TuMV reference isolate, UK1 (NC_002509), belongs to the B-host type and world-B phylogenetic group; UK1 infects many Brassica lines but only infects radish systemically with difficulty and without inducing apparent symptoms (Tomimura et al. 2003; Walsh 1989). Basal to all phylogenetic groups is a presumed ancestral group from orchids (Nguyen et al. 2013b). Many Asian isolates fall within the 
Asian-BR group; however, basal-BR isolates are emerging in Asia (Shi et al. 2007; Wang et al. 2009).

In order to analyze the origins of TuMV in Korea and to develop tools to screen for TuMV resistance, we collected isolates during a field survey of radish ( $R$. sativus), an important vegetable crop in Korea (Chung et al. 2015, 2016), from the major growing region (an area of about $19,000 \mathrm{~km}^{2}$ ). We generated full-length cDNA clones of 17 new isolates of TuMV and compared these with three previously characterized radish isolates (Han et al. 2016). To study the molecular and biological characteristics of these 17 TuMV isolates, we analyzed their differential pathogenicity on Nicotiana benthamiana and several genotypes of radish and Chinese cabbage (B. rapa ssp. pekinensis), phylogenetic relationships, and fullsequence alignments.

\section{MATERIALS AND METHODS}

Origin of TuMV isolates and plant materials. TuMV samples from radish were collected during a nationwide field survey of radish (R. sativus) crops from 2014 to 2016 in Korea. Infected sap was prepared with TuMV-infected field-collected radish leaves ground in $1 \mathrm{~mL}$ of $1 \times$ phosphate-buffered saline (PBS) buffer $\left(137 \mathrm{mM}\right.$ of $\mathrm{NaCl}, 2.7 \mathrm{mM}$ of $\mathrm{KCl}, 10 \mathrm{mM}$ of $\mathrm{Na}_{2} \mathrm{HPO}_{4}$, and $1.8 \mathrm{mM}$ of $\mathrm{KH}_{2} \mathrm{PO}_{4}, \mathrm{pH} 7.4$ ) per $100 \mathrm{mg}$ of leaf and mechanically inoculated to leaves of 2-week-old seedlings of $N$. benthamiana and $R$. sativus 'Dalgona' (Kwonnog Seed Co.) dusted with carborundum powder. Infectious clones (see below) were subsequently inoculated first to $N$. benthamiana and then by sap inoculation to seedlings of the Chinese cabbage cultivars Kenshin (HK Seed Co. Ltd.), lines SSD002 and SSD138 (hybrids between cultivars Kenshin and Chiifi; Molecular Genetics Laboratory, Chungnam National University), Norang (Alchannorang; KS Seed Co. Ltd., Korea), and Chusarang (CR Chusarang; Dongwon Nongsan Seed Co. Ltd.) and to radish cultivars Chunghwa (KS Seed Co. Ltd.) and Iljin (Dongwon Nongsan Seed Co. Ltd.). Chinese cabbage Norang and Chusarang, and radish Chunghwa and Iljin, are varieties commonly cultivated in Korea.

Total RNA extraction and cDNA synthesis. Total RNAs were extracted from TuMV-infected $N$. benthamiana leaves using TRIzol reagent (Life Technologies); all isolates originated from field-collected radish samples. Extracted total RNAs were kept at $-70^{\circ} \mathrm{C}$ and used for cDNA synthesis using a LeGene Express FirstStrand cDNA Synthesis System (LeGene Biosciences). The cDNAs were synthesized from pools of total RNAs grouped by region of origin of the isolates. 5'-Rapid amplification of cDNA ends (RACE) was also performed on pooled total RNAs from all samples, using 5'-RACE System for Rapid Amplification of cDNA Ends version 2.0 (Invitrogen).

Construction of full-length cDNA clones of TuMV. The construction of full-length cDNA clones utilized 5' and $3^{\prime}$ virusspecific primers for reverse transcription (RT) polymerase chain reaction (PCR) to generate full-length TuMV cDNA as $9.8-\mathrm{kb}$ fragments. PCR amplification was performed in a total volume of $50 \mu \mathrm{l}$ containing $2 \mu \mathrm{l}$ of template cDNA, $10 \mathrm{pmol}$ of R7_1/ 3_T7_ApaI_F primer (5'-GAGGGGCCCTAATACGACTCAC TATAGGAAAAATATAAAAACTCAACACAACATACACAAA $\overline{\text { ACG-3 }}{ }^{\prime}$ ) containing the T7 promoter sequence (underlined) and an ApaI site (bold), 10 pmol of R7_3/3_R_XmaI_T(30) primer (5' GAGCCCGGGTTTTTTTTTTTTTTTTTTTTTTTTTTTTTTGT CCCTTGCATCCTATCAAATG -3') containing an oligo T(30) sequence (underlined) and an XmaI site (bold), and $25 \mu \mathrm{l}$ of 2x PCR buffer for KOD FX Neo, 2 mM of dNTPs, 1 U of high-fidelity KOD FX Neo Taq polymerase (TOYOBO), and PCR-grade water to a final volume of $50 \mu \mathrm{l}$ (Supplementary Table S1). Conditions for PCR were initial denaturation at $94^{\circ} \mathrm{C}$ for $2 \mathrm{~min}$, followed by seven cycles of $10 \mathrm{~s}$ at $98^{\circ} \mathrm{C}, 30 \mathrm{~s}$ at $56^{\circ} \mathrm{C}$, and $5 \mathrm{~min}$ at $68^{\circ} \mathrm{C}$ and then by 28 cycles of $10 \mathrm{~s}$ at $98^{\circ} \mathrm{C}, 30 \mathrm{~s}$ at $65^{\circ} \mathrm{C}, 5 \mathrm{~min}$ at $68^{\circ} \mathrm{C}$, and then to $4^{\circ} \mathrm{C}$. Analysis of full-length PCR products of TuMV was conducted by
$0.8 \%$ agarose gel electrophoresis. The $9.8-\mathrm{kb}$ TuMV PCR products were digested with $A p a \mathrm{I}$ and $\mathrm{XmaI}$ restriction enzymes and cloned into vector pJY (Park et al. 2017) digested with the same enzymes. The recombinant plasmids were transformed into Escherichia coli (strain DH5 $\alpha$ ).

Sequencing of infectious cDNA clones and phylogenetic tree analysis. All constructed clones were sequenced by Macrogen Inc. using TuMV-specific primer sets. Primers were sequentially designed based on the initial sequence obtained. Nucleotide and predicted amino acid sequences were assembled and compared using DNAMAN version 5.2.10 (Lynnon BioSoft) and Biology WorkBench (http://workbench.sdsc.edu/), with three further Korean isolates (R007, R041, and R065; Han et al. 2016). Phylogenetic trees of TuMV genomic sequences were constructed using the maximum-likelihood method with 1,000 bootstrap replicates in MEGA version 7.0. Additional TuMV isolate sequences were obtained from the National Center for Biotechnology Information (NCBI) GenBank (Supplementary Table S2); Potato virus $Y$ (genus Potyvirus) genomic RNA and polyprotein sequences were used as outgroups to root trees.

Agroinfiltration and infectivity assays in N. benthamiana, and sequence determination. Full-length clones were evaluated for pathogenesis using agroinfiltration. Agrobacterium tumefaciens strain GV2260 was separately transformed with full-length TuMV cDNA clones; colonies were scraped from fresh plates and diluted to an optical density at $600 \mathrm{~nm}$ of approximately 0.6 in infiltration buffer (0.5 M of 2-(N-Morpholino)ethanesulfonic acid, $\mathrm{pH} 5.6$, and $1 \mathrm{M}$ of $\mathrm{MgCl}_{2}$ ) containing $150 \mathrm{mM}$ of 3', 5' -dimethoxy-4' hydroxyacetophenone (Sigma-Aldrich). Plants of $N$. benthamiana infiltrated with each of the constructed clones were either maintained in a growth chamber at 22 to $24^{\circ} \mathrm{C}$ or transferred after $24 \mathrm{~h}$ to the growth chamber. Agrobacterium infiltration was performed according to Lim et al. (2009). One clone representing each infectious sequence variant was selected for further work.

Evaluation of the pathogenicity of TuMV infectious clones in B. rapa ssp. pekinensis and R. sativus lines. First, individual full-length infectious clones were used for agroinfiltration of 2-week-old seedlings of $N$. benthamiana as described above. At 1 day postinoculation (dpi), the inoculated leaves of individual $N$. benthamiana plants were homogenized in $1 \mathrm{ml}$ of PBS buffer per $100 \mathrm{mg}$ of leaf and used for mechanical inoculation of carborundum-dusted leaves of three 2-week-old seedlings of B. rapa ssp. pekinensis (lines Kenshin, SSD002, and SSD138). Inoculations of each infectious clone variant were repeated twice. Each of the 17 selected infectious clones were subsequently mechanically inoculated to Chinese cabbage cultivars Norang and Chusarang and to radish cultivars Chunghwa and Iljin from agroinfiltrated tissue of $N$. benthamiana, as described above. Symptom expression was evaluated over 3 weeks postinoculation for radish and 4 weeks postinoculation for Chinese cabbage. Infection of upper, noninoculated leaves was evaluated at 4 dpi by RT-PCR. Total RNAs were extracted from newly generated leaves of $B$. rapa and $R$. sativus using TRIzol reagent, as above. Isolated total RNAs were used for cDNA synthesis by SuPrimeScript RT Premix (GeNet Bio). To detect TuMV, PCR was performed with Prime Taq DNA polymerase (GeNet Bio) and primers TuMV_CP_F_460/TuMV_CP_R_460. PCR conditions were 2 min at $94^{\circ} \overline{\mathrm{C}}$, followed by 30 cycles of $30 \mathrm{~s}$ at $94^{\circ} \mathrm{C}, 30 \mathrm{~s}$ at $54^{\circ} \mathrm{C}$, and $30 \mathrm{~s}$ at $72^{\circ} \mathrm{C}$ and a final cycle of $5 \mathrm{~min}$ at $72^{\circ} \mathrm{C}$.

\section{RESULTS}

Collection of TuMV radish isolates through a 2015 to 2016 nationwide survey. In order to analyze the origins of TuMV in Korea and develop tools to screen for TuMV resistance, we collected isolates during a 2015 to 2016 field survey of radish ( $R$. sativus) crops in Korea, and we selected isolates for further experiments based on differences in symptom expression in 
$N$. benthamiana and $R$. sativus. Field-collected plants infected with TuMV showed mosaic, mottle, and necrosis symptoms; these were collected from six provinces of Korea (Suwon-si, Gyeonggido; Daejeon; Buyeo-gun, Chungcheongnam-do; Chungju-si, Chungcheongbuk-do; Boeun-gun, Chungcheongbuk-do; and Mungyeong-si, Gyeongsangbuk-do) (Fig. 1).

Construction of infectious clones of $17 \mathrm{TuMV}$ isolates in a versatile binary vector. TuMV was propagated in $N$. benthamiana to maintain and increase the amount of virus; leaf mosaic and mottle appeared at 5 to $6 \mathrm{dpi}$ and systemic necrosis was observed with most isolates at 15 to 20 dpi. To generate the fulllength infectious cDNA clones, total RNA was extracted at $10 \mathrm{dpi}$ from composite samples of TuMV-infected $N$. benthamiana representing all isolates from a particular province and converted to cDNA. From the synthesized cDNA, double-stranded cDNA was amplified using primers R7_1/3_T7_ApaI_F and R7_3/ 3_R_XmaI_T(30); the PCR products of approximately $9.8 \mathrm{~kb}$ were digested with $A p a \mathrm{I}$ and $\mathrm{XmaI}$ for cloning into similarly digested binary vector $\mathrm{pJY}$ (Supplementary Fig. S1).

These cloning steps allowed us to successfully construct infectious clones suitable for both agroinfiltration and in vitro transcription in versatile binary vector pJY (Park et al. 2017). From 98 original full-length clones, we selected 64 infectious clones that induced symptoms in inoculated plants, fully sequenced all 64, and sorted them based on full-length sequence analysis into 17 distinct symptom-inducing clones of unique sequence (with between two and six clones per unique sequence; Supplementary
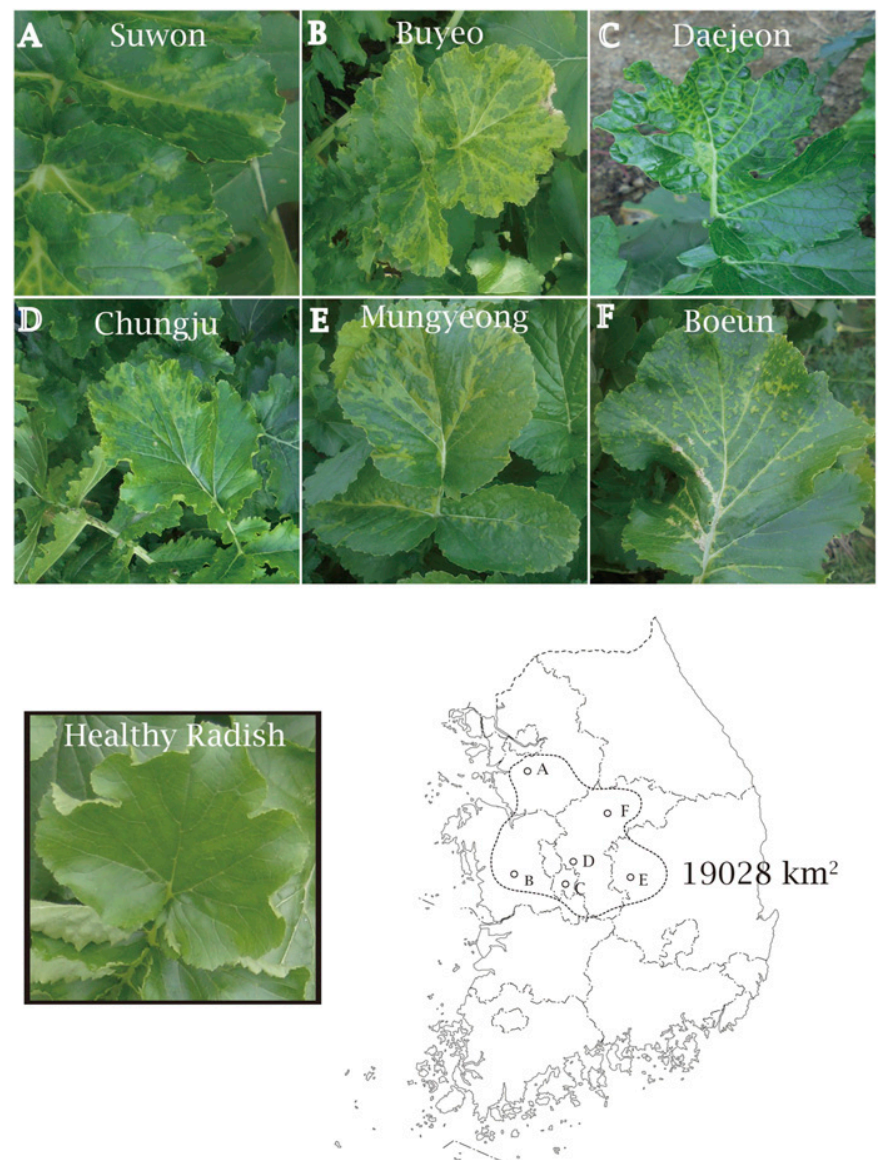

Fig. 1. The original Turnip mosaic virus (TuMV)-infected radish tissue of representative samples collected from six provinces of Korea: A, Suwon-si, Gyeonggi-do; B, Buyeo-gun, Chungcheongnam-do; C, Daejeon; D, Chungjusi, Chungcheongbuk-do; E, Mungyeong-si, Gyeongsangbuk-do; and F, Boeungun, Chungcheongbuk-do. The symptoms of collected Raphanus sativus samples and a healthy control are shown with the collection area on a map of Korea.
Table S3). The selected distinct clones were named HJY1 and HJY2 (from Buyeo-gun); GJS1, GJS2, GJS3, and GJS4 (from Mungyeong-si); KIH1 and KIH2 (from Chungju-si); DJ1, DJ2, DJ3, DJ4, DJ5, and DJ6 (from Daejeon); SW1 and SW2 (from Suwon-si); and BE (from Boeun).

Twenty-five randomly selected clones derived by 5'-RACE from total RNA pooled from all of the original radish field samples were sequenced, and the region corresponding to that derived from primer R7_1/3_T7_ApaI_F in the infectious clones was found to be identical in all 25 clones sequenced (data not shown), indicating a lack of variation between the field isolates in the immediate $5^{\prime}$ proximal sequence.

The differential pathogenicity of $17 \mathrm{TuMV}$ isolates in $N$. benthamiana, B. rapa, and $R$. sativus. To evaluate pathogenesis of the 17 isolates, all of the distinct infectious clones were evaluated for pathogenesis using agroinfiltration in $N$. benthamiana. We initially detected symptoms of each of the 17 isolates at $7 \mathrm{dpi}$, at which time there were no significant differences in symptoms; however, at $20 \mathrm{dpi}$, symptom differences were observed between the 17 isolates. "Mild" and "severe" isolates as described from this point forward refer to the response in $N$. benthamiana unless another host is specified. Isolates HJY1, HJY2 (Buyeo), and KIH2 (Chungju) showed malformation, mild mosaic, and mottle, whereas BE (Boeun) showed mild mosaic and yellowing. Unlike these four isolates, KIH1 (Chungju), GJS1, GJS2, GJS3, GJS4 (Mungyeong), SW1, SW2 (Suwon), DJ1, DJ2, DJ3, DJ4, DJ5, and DJ6 (Daejeon) isolates showed systemic necrosis after 20 days. With the exception of HJY1, HJY2, KIH2, and $\mathrm{BE}$, all of the new isolates induced severe necrosis resulting in a systemic hypersensitive response in $N$. benthamiana (Fig. 2). Under the same conditions, prior isolate R007 yielded malformation, mild mosaic, and mottle comparable to HJY1, HYJ2, and KIH2, whereas prior isolates R041 and R065 induced systemic necrosis by 20 days (Han et al. 2016; data not shown). All three isolates previously reported (R007, R041, and R065; Han et al. 2016) and the 17 new isolates induced mild mosaic and mottle symptoms in $R$. sativus lines Kenshin, SSD002, and SSD138 by 20 dpi (data not shown).

Additional inoculations of the 17 new infectious clones to radish cultivars Chunghwa and Iljin and to Chinese cabbage cultivars Norang and Chusarang yielded varying success in infection and differences in the symptoms in infected plants, and virus infection was confirmed by PCR (Fig. 3; Table 1). Radish Chunghwa and Chinese cabbage Norang had no significant differences in symptoms and infectivity for different TuMV isolates; Norang was not infected by any of these isolates, whereas all isolates infected Chunghwa with mild to severe symptoms (Table 1; Supplementary Fig. S2). However, various isolates showed differences in symptom development and infectivity in radish Iljin and Chinese cabbage Chusarang (Fig. 3). All 17 isolates infected Chusarang Chinese cabbage with symptoms varying from latent to mild or severe mosaic; the more severe symptoms typically included leaf distortion and obvious veinal association of the mosaic (Fig. 3). In contrast, no systemic infection of Iljin was detected for isolates GJS1, DJ1, DJ6, or KIH2, whereas all other isolates infected this variety systemically; infection was latent for isolates HJY1 and KIH1 (Fig. 3; Table 1).

There was therefore no correlation between symptoms in $N$. benthamiana and either Chinese cabbage or radish, nor any commonality between symptom expression in the different cruciferous species or cultivars. For example, the mild (on $N$. benthamiana) isolates HJY1 and HJY2, which have very similar polyprotein sequences, produced contrasting symptoms on Chinese cabbage Chusarang and radish Iljin; similarly the closely related isolates SW1 and SW2 were both severe in Chusarang but differed inversely in symptom expression on the two radish varieties (Table 1).

Sequence analysis of the 17 isolates and phylogenetic tree construction. The full sequences of the 17 infectious clones 
were determined using specific sequencing primers and were deposited in GenBank under accession numbers KX674726-KX674734 and KY111267-KY111274. Each genome is composed of 9,833 nucleotides (nt) excluding the poly(A) tail and encodes a predicted polyprotein of 3,164 amino acids (aa) for each isolate; these genomes are slightly larger than the 9,798 nt previously reported for most TuMV isolates (Nguyen et al. 2013b). TuMV isolate nucleotide sequence identities were compared with infectious clones of three previously characterized Korean isolates (R007, R041, and R065) (Han et al. 2016) using DNAMAN. Further analysis was performed using Biology WorkBench (http://workbench.sdsc. $\mathrm{edu} /$ ). Pairwise analysis among these 20 isolates revealed genomic nucleotide and polyprotein amino acid identities of $>87.9$ and $>95.7 \%$, respectively, with the highest nucleotide identities in $\mathrm{CP}, \mathrm{P} 1$, and HC-Pro and the highest amino acid identities in the HC-Pro (99.48\%), CI (99.14\%), and NIa-Pro (99.26\%) genes (Tables 2 and 3).

Pairwise comparisons were made of the $5^{\prime}$ - and $3^{\prime}$-untranslated regions (UTRs) and each coding region of the 17 new isolates, plus prior isolates R007 and R041, against the equivalent sequence of prior isolate R065 as a reference. Three of the four new isolates inducing only mild symptoms on $N$. benthamiana (HJY1, HJY2, and BE), plus prior mild isolate R007 (Han et al. 2016), showed lower identity to R065 across multiple (BE) or all (HJY1, HJY2, and $\mathrm{R} 007)$ regions of the genome, whereas mild isolate KIH2 was little differentiated from severe isolate $\mathrm{KIH} 1$ or other necrosis-inducing isolates. Mild isolates HJY1, HJY2, and R007 had very similar levels of identity to the reference isolate R065 across all regions of the genome at both nucleotide and amino acid levels, including both UTRs (Table 2).

When pairwise comparisons were made between the genomic (nucleotide) and polyprotein (amino acid) sequences of all 20 isolates, these results were confirmed; the three similar mild isolates HJY1, HJY2, and R007 showed similar, lower levels of identity ( $<89 \%$ nucleotide identity; $<97 \%$ amino acid identity) against all of the necrosis-inducing isolates and high levels of identity ( $>99 \%$ nucleotide or amino acid identity) to each other. Mild isolate BE showed similar levels of identity to all other isolates, but marginally lower identity against HJY1, HJY2, and R007 (both nucleotide and amino acid levels). Isolate KIH2 similarly showed obviously lower levels of identity (both nucleotides and amino acids) only against

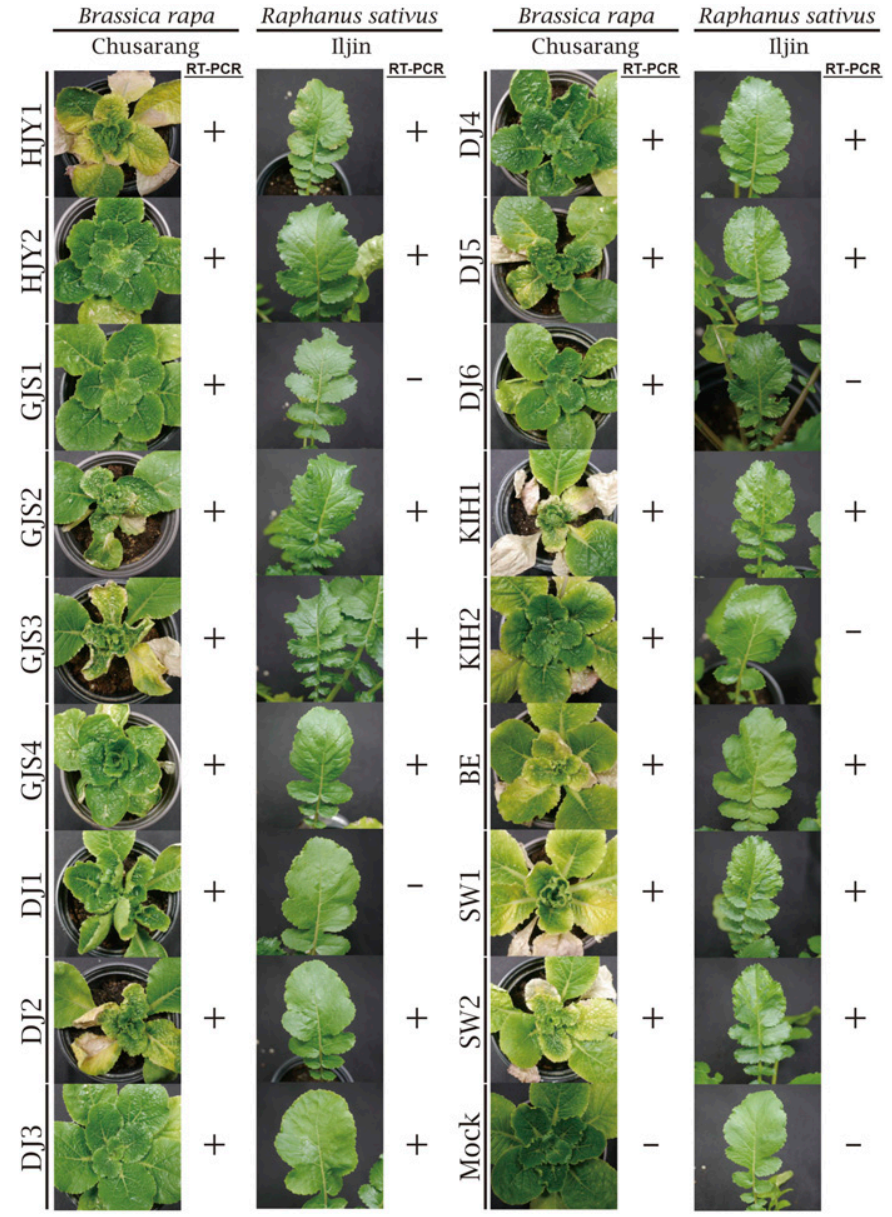

Fig. 3. Symptom development in commercial lines of radish (cultivar Iljin) and Chinese cabbage (cultivar Chusarang) infected by 17 representative Turnip mosaic virus (TuMV) isolates. Most of the isolates showed infectivity to both lines, but Iljin was resistant to isolates GJS1, DJ1, DJ6, and KIH2. Symbols indicate positive $(+)$ or negative $(-)$ results of reverse transcription polymerase chain reaction (RT-PCR) to detect TuMV in upper leaves. HJY = Buyeo-gun, $\mathrm{DJ}=$ Daejeon, GJS = Mungyeong-si, KIH = Chungju-si, BE = Boeun-gun, and $\mathrm{SW}=$ Suwon-si

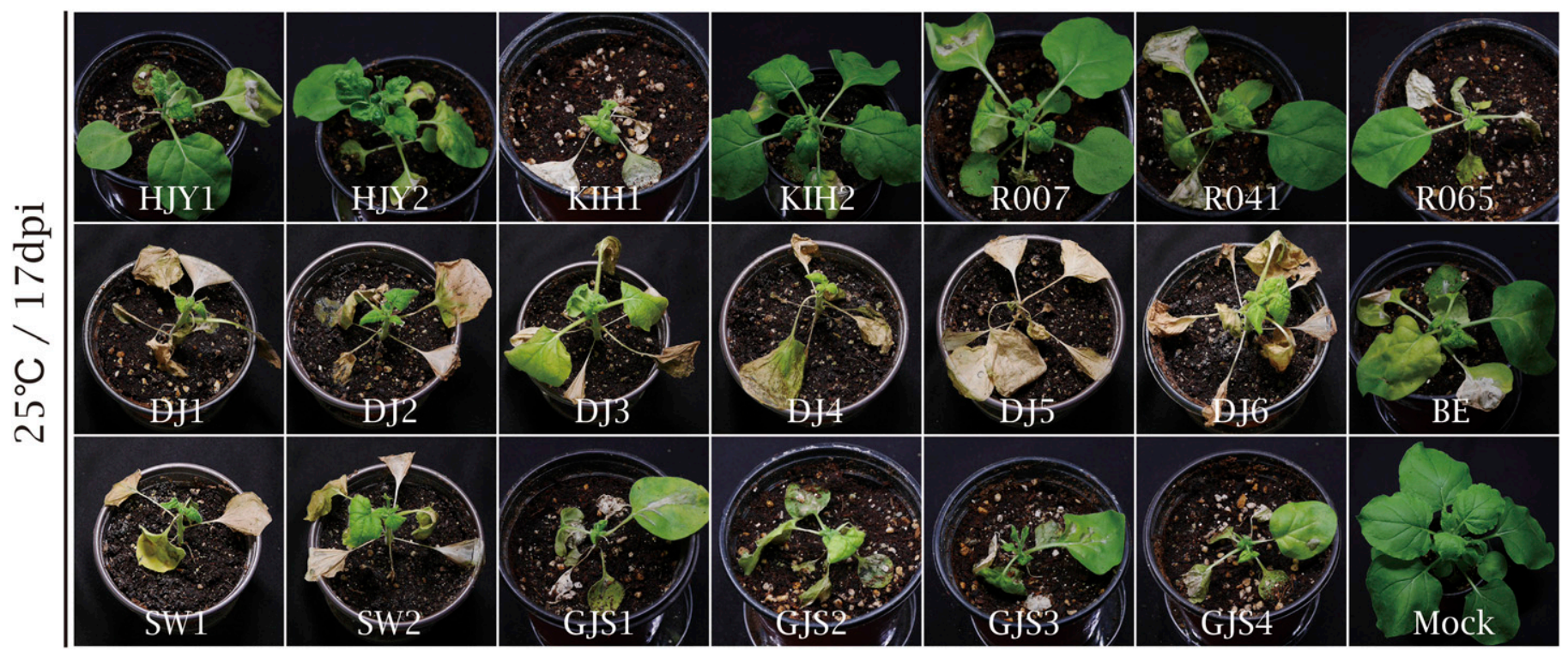

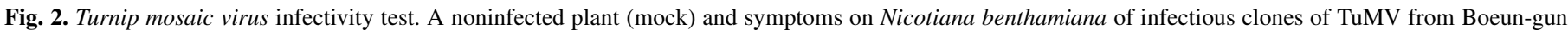

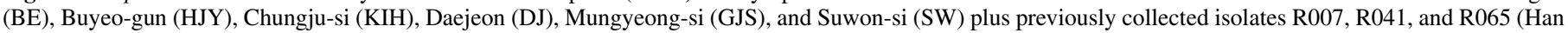

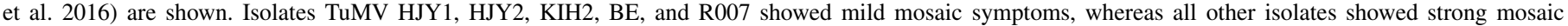
symptoms and systemic necrosis. Photographs were taken at 17 days postinoculation. 
mild isolates HJY1, HJY2, R007, and BE and $>99.9 \%$ identity to severe isolate KIH1 (Table 3).

Examination of a full polyprotein sequence alignment of all 20 isolates revealed multiple residues conserved between mild isolates HJY1, HJY2, and R007 (mild mosaic/mottle, without necrosis at 20 dpi) but differing from the consensus sequence and all isolates inducing severe symptoms (systemic necrosis prior to $20 \mathrm{dpi}$ ) in N. benthamiana (Fig. 2); several of these differential residues were

TABLE 1. Polymerase chain reaction (PCR) detection of Turnip mosaic virus (TuMV) isolates and chimeras after sap inoculation to two cultivars each of Chinese cabbage and radish ${ }^{\mathrm{a}}$

\begin{tabular}{|c|c|c|c|c|}
\hline \multirow[b]{2}{*}{ TuMV isolate or chimera ${ }^{\mathrm{b}}$} & \multicolumn{2}{|c|}{$\begin{array}{l}\text { Chinese cabbage } \\
\text { cultivar }\end{array}$} & \multicolumn{2}{|c|}{ Radish cultivar } \\
\hline & Norang & Chusarang & Chunghwa & Iljin \\
\hline HJY1 & - & $+/ \mathrm{S}^{\mathrm{c}}$ & $+/ \mathrm{M}$ & $+/ \mathrm{L}$ \\
\hline HJY2 & - & $+/ \mathrm{M}$ & $+/ \mathrm{M}$ & $+/ \mathrm{M}$ \\
\hline GJS1 & - & $+/ \mathrm{M}$ & $+/ \mathrm{S}$ & - \\
\hline GJS2 & - & $+/ \mathrm{S}$ & $+/ \mathrm{M}$ & $+/ \mathrm{M}$ \\
\hline GJS3 & - & $+/ \mathrm{S}$ & $+/ \mathrm{M}$ & $+/ \mathrm{M}$ \\
\hline GJS4 & - & $+/ \mathrm{M}$ & $+/ \mathrm{M}$ & $+/ \mathrm{M}$ \\
\hline DJ1 & - & $+/ \mathrm{M}$ & $+/ \mathrm{M}$ & - \\
\hline DJ2 & - & $+/ \mathrm{S}$ & $+/ \mathrm{M}$ & $+/ \mathrm{M}$ \\
\hline DJ3 & - & $+/ \mathrm{L}$ & $+/ \mathrm{M}$ & $+/ \mathrm{M}$ \\
\hline DJ4 & - & $+/ \mathrm{M}$ & $+/ \mathrm{M}$ & $+/ \mathrm{M}$ \\
\hline DJ5 & - & $+/ \mathrm{S}$ & $+/ \mathrm{M}$ & $+/ \mathrm{S}$ \\
\hline DJ6 & - & $+/ \mathrm{M}$ & $+/ \mathrm{M}$ & - \\
\hline KIH1 & - & $+/ \mathrm{S}$ & $+/ \mathrm{S}$ & $+/ \mathrm{L}$ \\
\hline KIH2 & - & $+/ \mathrm{M}$ & $+/ \mathrm{M}$ & - \\
\hline BE & - & $+/ \mathrm{S}$ & $+/ \mathrm{S}$ & $+/ \mathrm{M}$ \\
\hline SW1 & - & $+/ \mathrm{S}$ & $+/ \mathrm{M}$ & $+/ \mathrm{S}$ \\
\hline SW2 & - & $+/ \mathrm{S}$ & $+/ \mathrm{S}$ & $+/ \mathrm{M}$ \\
\hline Healthy & - & - & - & - \\
\hline Mock & - & - & - & - \\
\hline
\end{tabular}

a Minus signs indicate negative results of PCR (no symptoms), whereas positive signs indicate positive results of PCR. HJY = Buyeo-gun, $\mathrm{S}=$ severe symptoms, $\mathrm{M}=$ mild symptoms, and $\mathrm{L}=$ latent infection, $\mathrm{GJS}=$ Mungyeong-si, DJ $=$ Daejeon, KIH $=$ Chungju-si, BE = Boeun-gun, and $\mathrm{SW}=$ Suwon-si.

b The names of the four isolates (HJY1, HJY2, KIH2, and BE) inducing mild symptoms in Nicotiana benthamiana are shown in bold. Note that isolates GJS1, DJ1, DJ6, and KIH2 did not infect radish cultivar Iljin. See Figure 3 for images of inoculated plants and symptom expression at 4 weeks postinoculation for Chinese cabbage and 3 weeks postinoculation for radish. also present in isolate $\mathrm{BE}$, but not in $\mathrm{KIH} 2$, whereas four differential residues shared between HJY1, HJY2, and R007 (P3 T217I, Q229R, T234G, and A335T) were substituted by other differential residues in BE (T217M, Q229S, T234 N, and A335G) (Supplementary Fig. S3; Supplementary Table S4). Isolate KIH2 had only two unique differential residues (P1 residue 62I, and CI 158N) not also present in one or more severe isolates, whereas $\mathrm{CP} 23 \mathrm{E}$ was also present in only one severe isolate; in contrast, isolate BE had multiple unique differential residues spread across all TuMV genes except NIa-Pro and NIb (RdRp). The isolates inducing mild symptoms in $N$. benthamiana therefore appear to segregate into three classes: (i) HJY1, HJY2, and R007; (ii) KIH2; and (iii) BE.

The complete nucleotide sequences of the 20 Korean isolates (containing the 17 new isolates determined here and three previous isolates; Han et al. 2016) and 33 previously characterized TuMV isolates (Nguyen et al. 2013a) from NCBI were subjected to phylogenetic analysis. All of the TuMV isolates were clustered into four previously described groups (Nguyen et al. 2013a). The pathotypes of TuMV isolates are divided into two types: Brassica (B; can infect Brassica spp. but not Raphanus spp.) and Brassica-Raphanus (BR; can infect both Brassica and Raphanus spp.) (Ohshima et al. 2002). The phylogenetic analysis showed that all 17 new isolates belong to the basal-BR group, together with the three previously characterized Korean isolates (Han et al. 2016), divided between two subclades and were most closely related to isolates from Japan and Italy (Fig. 4). It is noteworthy that new mild isolates HJY1, HJY2, and BE were grouped with previously identified mild isolate R007 in one subclade, whereas all of the other new isolates, including mild isolate $\mathrm{KIH} 2$, were grouped with previously identified necrosisinducing isolates R041 and R065 (Han et al. 2016) in the larger subclade (Fig. 4).

Unlike the grouping of four mild isolates into a distinct subclade, no obvious phylogenetic grouping could be discerned for the four isolates that failed to infect radish cultivar Iljin (GJS1, DJ1, DJ6, and KIH2). Comparison of the aligned amino acid sequences similarly reveals no amino acid residues in any cistron that are uniquely conserved between these four isolates. All of the residues of $\mathrm{KIH} 2$ that differ from the consensus sequence, except for polyprotein residues 62I (in P1) and $1385 \mathrm{~N}$ (in CI) unique to $\mathrm{KIH} 2$, are shared with at least KIH1 (latent infection in Iljin) and in several cases also with multiple other isolates also infecting Iljin. There are

TABLE 2. Comparison of untranslated regions (UTRs) and gene nucleotide (NT) and amino acid (AA) sequence identities between severe Turnip mosaic virus (TuMV) isolate R065 and 19 other Korean TuMV isolates from radish ${ }^{\mathrm{a}}$

\begin{tabular}{|c|c|c|c|c|c|c|c|c|c|c|c|c|c|c|c|c|c|c|c|c|c|c|}
\hline \multirow[b]{2}{*}{ Isolate } & \multirow{2}{*}{$\frac{5^{\prime}-\mathrm{UTR}}{\mathrm{NT}}$} & \multicolumn{2}{|c|}{$\mathrm{P} 1$} & \multicolumn{2}{|c|}{ HC-Pro } & \multicolumn{2}{|c|}{ P3 } & \multicolumn{2}{|c|}{$6 \mathrm{~K} 1$} & \multicolumn{2}{|c|}{ CI } & \multicolumn{2}{|c|}{$6 \mathrm{~K} 2$} & \multicolumn{2}{|c|}{ NIa-VPg } & \multicolumn{2}{|c|}{ NIa-Pro } & \multicolumn{2}{|c|}{$\mathrm{NIb}$} & \multicolumn{2}{|c|}{$\mathrm{CP}$} & \multirow{2}{*}{$\frac{3^{\prime}-\mathrm{UTR}}{\mathrm{NT}}$} \\
\hline & & NT & $\mathrm{AA}$ & NT & AA & NT & AA & NT & AA & NT & AA & NT & AA & NT & AA & NT & AA & NT & $\mathrm{AA}$ & NT & AA & \\
\hline DJ1 & 98.45 & 98.43 & 97.24 & 98.84 & 99.34 & 98.78 & 98.59 & 98.08 & 100 & 98.96 & 99.22 & 100 & 100 & 97.92 & 97.40 & 98.08 & 100 & 98.39 & 99.23 & 98.61 & 98.26 & 100 \\
\hline DJ2 & 99.22 & 99.36 & 98.62 & 99.27 & 99.78 & 98.78 & 99.15 & 98.08 & 100 & 98.91 & 99.38 & 100 & 100 & 98.44 & 98.96 & 98.77 & 100 & 98.52 & 99.23 & 98.61 & 98.26 & 100 \\
\hline DJ3 & 99.22 & 99.45 & 99.17 & 99.49 & 99.56 & 99.53 & 99.44 & 98.08 & 100 & 99.12 & 99.38 & 100 & 100 & 98.44 & 98.44 & 99.31 & 100 & 98.32 & 98.84 & 98.73 & 97.92 & 100 \\
\hline DJ4 & 98.45 & 98.34 & 97.24 & 98.84 & 99.34 & 98.78 & 98.59 & 98.08 & 100 & 99.02 & 99.38 & 100 & 100 & 98.09 & 97.40 & 98.22 & 100 & 98.32 & 99.23 & 98.84 & 98.61 & 100 \\
\hline DJ5 & 98.45 & 98.25 & 96.96 & 98.76 & 99.34 & 98.78 & 98.59 & 98.08 & 100 & 99.02 & 99.38 & 100 & 100 & 98.09 & 97.40 & 98.22 & 100 & 98.26 & 99.03 & 98.73 & 98.61 & 100 \\
\hline DJ6 & 98.45 & 99.36 & 99.17 & 99.49 & 99.78 & 98.87 & 98.87 & 98.08 & 100 & 99.22 & 99.53 & 99.37 & 100 & 97.22 & 97.40 & 99.04 & 100 & 98.58 & 99.23 & 99.19 & 98.61 & 100 \\
\hline GJS1 & 97.67 & 98.90 & 97.51 & 99.27 & 99.78 & 98.78 & 98.59 & 98.08 & 100 & 99.12 & 99.38 & 100 & 100 & 99.48 & 98.96 & 98.63 & 100 & 99.48 & 99.42 & 98.73 & 98.61 & 100 \\
\hline GJS2 & 97.67 & 98.99 & 97.79 & 99.27 & 99.78 & 98.78 & 98.59 & 98.08 & 100 & 99.07 & 99.38 & 100 & 100 & 99.65 & 99.48 & 98.77 & 100 & 99.55 & 99.81 & 98.73 & 98.61 & 100 \\
\hline GJS3 & 97.67 & 98.90 & 97.79 & 99.27 & 99.78 & 98.78 & 98.59 & 98.08 & 100 & 99.07 & 99.22 & 100 & 100 & 99.65 & 99.48 & 98.77 & 100 & 99.55 & 99.81 & 98.73 & 98.61 & 100 \\
\hline GJS4 & 97.67 & 98.99 & 97.79 & 99.27 & 99.78 & 98.69 & 98.31 & 98.08 & 100 & 99.12 & 99.38 & 100 & 100 & 99.65 & 99.48 & 98.77 & 100 & 99.61 & 99.81 & 98.73 & 98.61 & 100 \\
\hline HJY1 & 94.57 & 87.48 & 89.78 & 87.34 & 98.69 & 87.14 & 93.52 & 91.03 & 100 & 90.48 & 98.91 & 83.65 & 94.34 & 85.42 & 92.71 & 83.81 & 96.71 & 86.01 & 96.13 & 90.51 & 96.18 & 95.75 \\
\hline HJY2 & 93.80 & 87.48 & 89.78 & 87.34 & 98.69 & 87.14 & 93.52 & 91.03 & 100 & 90.48 & 98.91 & 83.65 & 94.34 & 85.42 & 92.71 & 83.68 & 96.71 & 86.07 & 96.32 & 90.51 & 96.18 & 95.75 \\
\hline KIH1 & 99.22 & 99.82 & 99.72 & 99.78 & 99.78 & 99.91 & 99.72 & 99.36 & 100 & 99.43 & 99.53 & 100 & 100 & 98.61 & 98.44 & 99.59 & 100 & 98.52 & 99.23 & 99.31 & 98.61 & 100 \\
\hline KIH2 & 99.22 & 99.63 & 99.45 & 99.71 & 99.78 & 99.91 & 99.72 & 99.36 & 100 & 99.38 & 99.38 & 100 & 100 & 98.61 & 98.44 & 99.59 & 100 & 98.58 & 99.42 & 99.31 & 98.61 & 100 \\
\hline BE & 99.22 & 98.99 & 97.79 & 97.38 & 99.34 & 80.47 & 89.01 & 82.69 & 96.15 & 85.66 & 97.52 & 81.76 & 84.91 & 82.81 & 91.15 & 84.09 & 96.71 & 89.30 & 97.29 & 98.84 & 98.26 & 100 \\
\hline SW1 & 98.45 & 99.17 & 98.34 & 99.27 & 99.78 & 98.78 & 99.15 & 97.44 & 100 & 98.76 & 99.22 & 98.11 & 100 & 97.92 & 97.40 & 98.77 & 100 & 98.39 & 99.23 & 98.84 & 98.61 & 100 \\
\hline SW2 & 98.45 & 99.17 & 98.34 & 99.27 & 99.78 & 98.87 & 99.15 & 97.44 & 100 & 98.76 & 99.22 & 98.11 & 100 & 97.92 & 97.40 & 98.77 & 100 & 98.45 & 99.42 & 98.84 & 98.61 & 99.53 \\
\hline R007 & 94.57 & 87.38 & 89.78 & 87.26 & 98.47 & 87.14 & 93.52 & 91.67 & 100 & 90.42 & 98.45 & 83.65 & 94.34 & 85.24 & 92.19 & 83.54 & 96.71 & 86.01 & 96.13 & 90.63 & 95.83 & 95.28 \\
\hline R041 & 98.45 & 98.80 & 97.24 & 99.13 & 99.56 & 99.34 & 99.44 & 98.08 & 100 & 99.17 & 99.07 & 98.74 & 100 & 98.78 & 98.96 & 98.49 & 99.18 & 98.45 & 99.03 & 99.07 & 98.61 & 100 \\
\hline
\end{tabular}

${ }^{\mathrm{a}}$ HC-Pro $=$ Helper component protease, $\mathrm{CI}=$ cylindrical inclusion, NIa-Pro $=$ nuclear inclusion protein a protease, $\mathrm{VPg}=$ virus-encoded genome-linked protein, NIb $=$ nuclear inclusion protein $\mathrm{b}$ (RdRp), $\mathrm{CP}=$ coat protein, DJ = Daejeon, GJS = Mungyeong-si, HJY = Buyeo-gun, KIH = Chungju-si, BE = Boeun-gun, and SW = Suwon-si. Mild symptom TuMV isolates are highlighted in bold. Note that mild isolates R007, HJY1, and HJY2 are differentiated from all severe isolates in all gene segments except for the 6K1 amino acid sequence, whereas mild isolate BE is also differentiated from R007, HJY1, and HJY2 in P3, NIa-VPg, NIa-Pro, and NIb and is the only isolate differentiated in the 6K1 amino acid sequence. In contrast, mild isolate KIH2 is not clearly differentiated from severe isolates in any genome segment by either nucleotide or amino acid identity. 
similarly no residues conserved only between GJS1, DJ1, and DJ6, which are candidates for an avirulence determinant for Iljin.

\section{DISCUSSION}

Viruses of the genus Potyvirus cause great economic damage to various kinds of crops worldwide. Functions, features, and host interactions of several crucial potyviruses, including TuMV, have been studied. Many TuMV strains are known as a result of the broad host range and geographical distribution of the virus (Nguyen et al. 2013b; Shi et al. 2007; Tomitaka and Ohshima 2006; Tomlinson 1987; Walsh and Jenner 2002), with determination of strains dependent on host resistance genes and viral pathogenicity determinants. However, pathogenicity determinants of many strains of TuMV have not been clearly identified, although HC-Pro has been implicated (Kozubek et al. 2007), as has P3 (Jenner et al. 2003; Suehiro et al. 2004). In order to study the molecular and biological characteristics of TuMV isolates and their gene function (including pathogenesis), it is necessary to construct infectious cDNA clones. TuMV full-length infectious clones have expanded our knowledge of TuMV genomic organization and identification of the involvement of each viral protein in potyvirus basic biology, viral replication, virus-host interactions, polyprotein processing, cell-tocell movement, long-distance movement, aphid transmission, and seed transmission (Casteel et al. 2014; Rojas et al. 1997; UrcuquiInchima et al. 2001; Vijayapalani et al. 2012; Walsh and Jenner 2002; Zubareva et al. 2013).

In this study, we constructed 64 infectious clones from which we selected 17 isolates of TuMV having sequences distinct from each other. Pathogenicity assays of these 17 isolates show that there are 13 isolates inducing strong symptoms of systemic necrosis in $N$. benthamiana similar to that of previously characterized isolates R041 and R065 (KIH1, GJS1, GJS2, GJS3, GJS4, SW1, SW2, DJ1, DJ2, DJ3, DJ4, DJ5, and DJ6). Four other isolates (HJY1, HJY2, $\mathrm{KIH} 2$, and $\mathrm{BE}$ ) induce mild mosaic and stunting equivalent to the previously characterized R007 (Han et al. 2016). The phylogenetic tree shows that all 20 of these Korean TuMV isolates belong to the basal-BR group and have the closest relationship to Japanese and
Italian isolates (Fig. 4); this confirms that the basal-BR group has become established in Korea as well as in China (Shi et al. 2007; Wang et al. 2009). Comparison of the sequence identities and distribution of differential residues between genes suggests that there are three classes of mild isolates among the 20 Korean isolates examined, represented by (i) HJY1, HJY2, and R007; (ii) $\mathrm{KIH} 2$; and (iii) BE.

In the work presented here, we have identified close phylogenetic similarity between mild isolates HYJ1, HJY2, and R007, with slightly less similarity to isolate $\mathrm{BE}$, whereas $\mathrm{KIH} 2$ falls in the middle of a clade of isolates inducing systemic necrosis in $N$. benthamiana (Fig. 3). However, whereas HJY1, HJY2, and R007 share multiple residues throughout the polyprotein that are found only in these three mild isolates, BE has many other residues (including more than 20 in P3) that are unique to this isolate. In contrast, the $\mathrm{KIH} 2$ polyprotein has only two residues unique to this mild isolate, V62I (in P1) and Y1385 N (in CI). In an accompanying article, we have created chimeras between mild isolate HJY1 and severe isolate KIH1 to identify the regions responsible for the differences in pathogenicity (Kim et al. 2018, unpublished data). Future work is required to create chimeras between $\mathrm{KIH} 1$ and each of the mild isolates KIH2 and BE to identify the location of the changes in these isolates which presumably induce mild symptoms through a different mechanism than in isolates HJY1, HJY2, and R007.

The conservation of differential residues in isolates HJY1, HJY2, $\mathrm{R} 007$, and BE, and their mild phenotype in N. benthamiana, suggests that these isolates may have become adapted to a host (or hosts) other than radish, as HYJ1, HJY2, and R007 all share four differential residues in $\mathrm{P} 3$, whereas isolate $\mathrm{BE}$ has four separate differential residues at the same positions. Variation in P3 has previously been associated with differences in pathogenicity in TuMV (Jenner et al. 2002, 2003; Suehiro et al. 2004) and in Plum pox virus (PPV) in different host species (Sáenz et al. 2000). It is possible that another host species that serves as a reservoir of isolates similar to HYJ1, HJY2, and R007, or similar to BE, will be found.

We note that the extreme $5^{\prime}$ sequences of all of our infectious clones were derived from the RT-PCR primer and therefore may not

TABLE 3. Matrix of pairwise genomic nucleotide and polyprotein amino acid sequences of 20 Korean Turnip mosaic virus (TuMV) isolates from radish ${ }^{\mathrm{a}}$

\begin{tabular}{|c|c|c|c|c|c|c|c|c|c|c|c|c|c|c|c|c|c|c|c|c|}
\hline & $\mathrm{BE}^{*}$ & DJ1 & DJ2 & DJ3 & DJ4 & DJ5 & DJ6 & GJS1 & GJS2 & GJS3 & GJS4 & HJY1* & HJY2* & KIH1 & $\mathrm{KIH} 2 *$ & SW1 & SW2 & R007* & R041 & R065 \\
\hline BE* & - & 90.08 & 90.14 & 90.1 & 90.09 & 90.01 & 90.23 & 90.10 & 4 & 0.13 & 90.13 & 88.82 & 3.72 & 90.24 & 90.21 & 90.20 & 90.19 & 88.72 & 90.04 & 90.03 \\
\hline DJ1 & 96.59 & - & 98.92 & 98.88 & 99.90 & 9.87 & 99.02 & 98.84 & 98.87 & 98.86 & 98.86 & 87.94 & 87.93 & 99.03 & 99.00 & 98.84 & 98.85 & 87.91 & 98.67 & 98.64 \\
\hline $\mathrm{DJ} 2$ & 96.65 & 99.27 & - & 99.15 & 98.95 & 98.91 & 99.28 & 99.11 & 99.14 & 99.13 & 99.13 & 88.10 & 88.09 & 99.29 & 99.27 & 99.08 & 99.09 & 88.07 & 98.93 & 98.90 \\
\hline DJ3 & 96.59 & 99.02 & 99.43 & - & 98.91 & 98.87 & 99.23 & 99.04 & 99.07 & 99.06 & 99.06 & 88.14 & 88.13 & 99.58 & 99.55 & 99.02 & 99.03 & 88.11 & 99.01 & 99.08 \\
\hline DJ4 & 96.68 & 99.91 & 99.34 & 99.08 & - & 99.94 & 99.05 & 98.87 & 98.90 & 98.89 & 98.89 & 87.97 & 87.96 & 99.06 & 99.03 & 98.87 & 98.88 & 87.94 & 98.64 & 98.67 \\
\hline DJ5 & 96.62 & 99.84 & 99.27 & 99.02 & 99.94 & - & 99.01 & 98.83 & 98.87 & 98.85 & 98.85 & 87.97 & 87.96 & 99.02 & 98.99 & 98.83 & 98.84 & 87.94 & 98.68 & 98.63 \\
\hline DJ6 & 96.71 & 99.34 & 99.62 & 99.43 & 99.40 & 99.34 & - & 99.16 & 99.20 & 99.19 & 99.19 & 88.13 & 88.12 & 99.38 & 99.36 & 99.17 & 99.18 & 88.10 & 98.99 & 98.99 \\
\hline GJS1 & 96.46 & 99.02 & 99.43 & 99.12 & 99.08 & 99.02 & 99.37 & - & 99.92 & 99.91 & 99.91 & 87.93 & 87.92 & 99.18 & 99.15 & 3.94 & 98.95 & 87.90 & .30 & 99.08 \\
\hline GJS2 & 96.59 & 99.15 & 99.56 & 99.24 & 99.21 & 99.15 & 99.49 & 99.87 & - & 99.95 & 99.95 & 87.94 & 87.93 & 99.21 & 99.18 & 98.97 & 98.98 & 87.91 & 99.34 & 99.12 \\
\hline GJS3 & 96.55 & 99.12 & 99.53 & 99.21 & 99.18 & 99.12 & 99.46 & 99.84 & 99.97 & - & 100.0 & 87.95 & 87.94 & 99.20 & 99.17 & 98.96 & 98.97 & 87.92 & 99.33 & 99.11 \\
\hline GJS4 & 96.55 & 99.12 & 99.53 & 99.21 & 99.18 & 99.12 & 99.46 & 99.84 & 99.97 & 100 & - & 87.95 & 87.94 & 99.20 & 99.17 & 98.96 & 98.97 & 87.92 & 98.33 & 99.11 \\
\hline HJY1* & 96.08 & 96.02 & 96.33 & 96.37 & 96.11 & 96.05 & 96.27 & 96.02 & 96.14 & 96.11 & 96.11 & - & 99.96 & 88.13 & 88.10 & 88.08 & 88.07 & 99.80 & 87.97 & 87.94 \\
\hline HJY2* & 96.02 & 96.05 & 96.37 & 96.40 & 96.14 & 96.08 & 96.30 & 96.05 & 96.18 & 96.14 & 96.14 & 99.94 & - & 88.12 & 88.09 & 88.07 & 88.06 & 99.79 & 87.96 & 87.93 \\
\hline KIH1 & 96.62 & 99.18 & 99.59 & 99.59 & 99.24 & 99.18 & 99.59 & 99.27 & 99.40 & 99.37 & 99.37 & 96.37 & 96.40 & - & 99.95 & 99.17 & 99.18 & 88.19 & 99.21 & 99.40 \\
\hline $\mathrm{KIH} 2 *$ & 96.59 & 99.15 & 99.56 & 99.56 & 99.21 & 99.15 & 99.56 & 99.24 & 99.37 & 99.43 & 99.34 & 96.33 & 96.37 & 99.91 & - & 99.13 & 99.15 & 88.07 & 99.18 & 99.37 \\
\hline SW1 & 96.62 & 99.24 & 99.56 & 99.30 & 99.30 & 99.24 & 99.56 & 99.24 & 99.37 & 99.43 & 99.34 & 96.27 & 96.30 & 99.46 & 99.43 & - & 99.97 & 88.05 & 98.81 & 98.76 \\
\hline SW2 & 96.65 & 99.27 & 99.59 & 99.34 & 99.34 & 99.27 & 99.59 & 99.27 & 99.40 & 99.37 & 99.37 & 96.30 & 96.33 & 99.49 & 99.46 & 99.97 & - & 88.04 & 98.82 & 98.78 \\
\hline R007* & 95.80 & 95.83 & 96.14 & 96.18 & 95.92 & 95.86 & 96.08 & 95.83 & 95.95 & 95.92 & 95.92 & 99.72 & 99.72 & 96.18 & 96.14 & 96.08 & 96.11 & - & 87.96 & 87.90 \\
\hline R041 & 96.40 & 98.83 & 99.24 & 99.05 & 98.89 & 98.83 & 99.18 & 99.27 & 99.40 & 99.37 & 99.37 & 96.02 & 96.05 & 99.21 & 99.18 & 99.12 & 99.15 & 95.76 & - & 98.93 \\
\hline R065 & 96.21 & 98.83 & 99.24 & 99.18 & 98.89 & 98.83 & 99.24 & 99.12 & 99.24 & 99.21 & 99.21 & 95.92 & 95.95 & 99.46 & 99.43 & 99.12 & 99.15 & 95.73 & 98.96 & - \\
\hline
\end{tabular}

${ }^{a} \mathrm{BE}=$ Boeun-gun, DJ = Daejeon, GJS = Mungyeong-si, HJY = Buyeo-gun, KIH = Chungju-si, and SW = Suwon-si. Amino acid identity is shown below the diagonal, whereas nucleotide identity is shown above the diagonal. Names of isolates inducing mild symptoms in Nicotiana benthamiana are indicated by an asterisk (*), and comparisons of their nucleotide and amino acid sequences are highlighted in bold and italicized, respectively. Note that mild isolates BE, HJY1, HJY2, and R007 have lower amino acid identity to all other isolates except each other and that BE has lower identity to all isolates; however, mild isolate KIH2 is not differentiated. Mild isolates other than $\mathrm{KIH} 2$ have lower identities ( $<97 \%$ amino acid identity and $<91 \%$ nucleotide identity) to all severe isolates (which have $>98 \%$ amino acid identity and $>98 \%$ nucleotide identity to other severe isolates). KIH2 has low identities ( $<97 \%$ amino acid, $<91 \%$ nucleotide) only to the other "mild" isolates, whereas HJY1, HJY2, and R007 have high identities ( $>99 \%$ for both amino acid and nucleotide identities) only to each other. Three classes of mild isolates (R007/HJY1/HJY2, BE, and $\mathrm{KIH} 2$ ) are also supported by examination of polyprotein amino acid alignment based on the numbers of residues unique to the "mild" isolate classes (and in the case of R007/HJY1/HJY2, shared between them). 
exactly reflect the sequences of the isolates in the original fieldcollected plants. However, the $5^{\prime}$ primer used to amplify the infectious clones shares 33 of 37 residues identified by SimónBuela et al. (1997) as the consensus sequence of isolates of 14 distinct potyvirus species. The four residues varying from the consensus are identical to the TuMV sequence included in the alignment (Simón-Buela et al. 1997; data not shown), and 5'-RACE from a mixed pool of the original radish isolates revealed no variation from the sequence utilized in the primer used to generate the infectious clones. Because we have performed all of our analyses and symptom comparisons using the infectious clones, any observed differences in symptoms or infectivity in the hosts examined are therefore not the result of any possible differences in the extreme $5^{\prime}$-UTR of the original field isolates, but of sequence differences elsewhere in the infectious clones.

Similarly, whereas any differences in host responses observed under controlled conditions may not reflect the behavior of the same isolates under field conditions, we believe that the observed variations in symptoms and cultivar susceptibility are directly related to differences between the sequences of the infectious clones.

However, among 17 isolates with which we performed infectivity and pathogenesis tests, we observed differential symptom development in radish and Chinese cabbage than in N. benthamiana.
Isolate HJY1, which induced mild symptoms in $N$. benthamiana, showed very severe symptoms in Brassica rapa; all of the isolates infected Chinese cabbage cultivar Chusarang (Fig. 3), whereas none infected Norang. All of the isolates infected radish cultivar Chunghwa, whereas four failed to infect Iljin (Fig. 3); no residues could be identified that were conserved between these four isolates (GJS1, DJ1, K1H2, and DJ6) and which differed from the consensus sequence that are potential avirulence determinants for Iljin, although creation of chimeric constructs between isolate DJ5 (inducing severe symptoms on Iljin) and each the four isolates not able to infect this host might allow identification of residues associated with avirulence in Iljin.

Suehiro et al. (2004) identified six amino acid positions in P3 with similar residue characteristics in 20 radish-infecting BR strain isolates. The equivalent residues in the 20 Korean radish isolates used here were absolutely conserved but differed from some of the isolates examined by Suehiro et al. (2004). The respective residues for Korean (this work) and other isolates were as follows: position 203I versus Q, K, or R; 231Y versus Y, H, or K; 268I versus I or M; 279/280TI versus TI or KM; and 286R versus R, H, or Q. As all of the Korean isolates infect radish systemically, the variation at residue 203I, although distinct from the previously reported Q, K, and $\mathrm{R}$, is clearly tolerated for systemic infection of radish; our

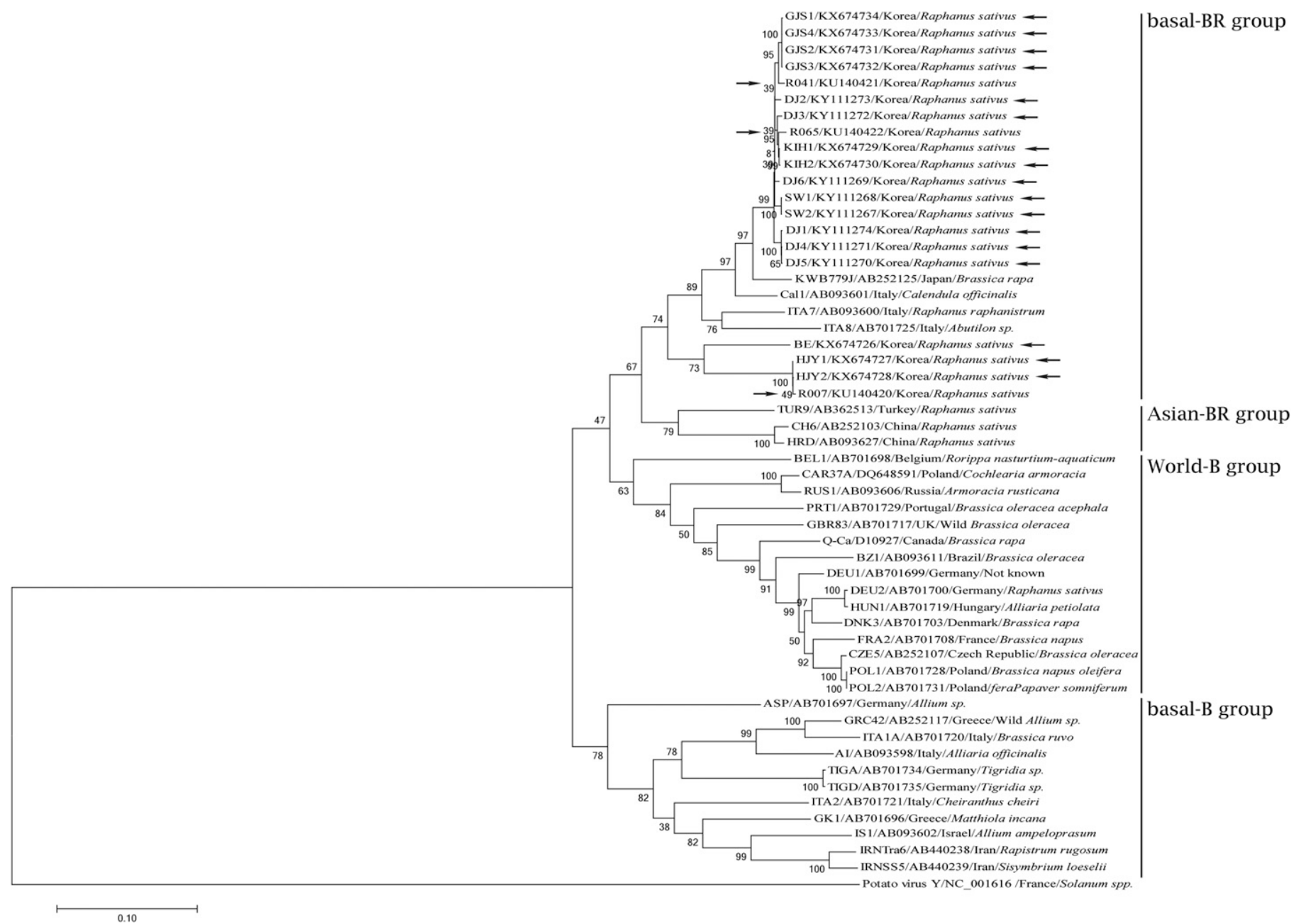

Fig. 4. A phylogenetic tree constructed by the maximum-likelihood method with 1,000 bootstrap replicates, based on the complete nucleotide sequences of the Turnip mosaic virus (TuMV) polyprotein. The genomes of 33 isolates of TuMV for analysis were obtained from the National Center for Biotechnology Information GenBank. The genome sequence of Potato virus $Y$ was used as the outgroup to root the tree. Isolates are indicated in the tree by isolate name, accession number, country, and origin of the host, respectively. All isolates of TuMV represented by infectious clones fall within the basal-BR group. The positions of the 17 new infectious clones are marked with arrows (left arrow) to the right of the isolate label, and the infectious clones of prior isolates R007, R041, and R065 with arrows (right arrow) to the left of the isolate label. B = the pathotype can infect Brassica spp. but not Raphanus spp., and BR = the pathotype can infect both Brassica and Raphanus spp. 
infectious clones also differ in their ability to infect Iljin. The availability of the new infectious clones will allow future mutagenesis to further examine the proposed determinant of systemic infection of radish (Suehiro et al. 2004). The P3 residues 153 and 312 identified by Jenner et al. $(2002,2003)$ as associated with overcoming resistance conferred by TuRBO3 and TuRBO4 are identical $(153 \mathrm{I}, 312 \mathrm{~F})$ in all of the new Korean isolates and are therefore not related to the observed symptom differences.

The differences between relative symptom expression-or even infectivity-in different hosts suggests that different viral determinants are important in these interactions; it has previously been noted in the TuMV/B. rapa pathosystem that symptom type is dependent on the particular virus isolates and plant genotypes examined (Fujiwara et al. 2011). It has also been demonstrated that different TuMV resistance genes interact with different viral determinants; thus, the $\mathrm{P} 3$ protein is the determinant interacting with TuRBO3 (Jenner et al. 2003) and TuRBO4 (Jenner et al. 2002), and CI for TuRBO5 (Jenner et al. 2002), TuRBO1/TuRBOIb (Jenner et al. 2000; Walsh et al. 2002), and Rnt1-1 in Chinese cabbage, a gene probably differentiated from TuRBO1b (Fujiwara et al. 2011). The interaction of different potyviral proteins with different hosts is not limited to TuMV; the PPV region containing the C-terminal portion of the $\mathrm{P} 3$ gene and the $6 \mathrm{~K} 1$ gene was shown to be associated with symptom phenotype in $N$. clevelandii and Pisum sativum (Saenz et al. 2000), as well as plum but not peach (Dallot et al. 2001), whereas additional determinants of host specificity for $N$. clevelandii and peach were identified in the $\mathrm{N}$-terminal region of the PPV CP (Salvador et al. 2008).

Unfortunately, genetic information on the resistance genes present in the Korean radish and Chinese cabbage genotypes examined here is not available, nor is the number of genes associated with TuMV resistance in these lines. In the absence of such information, an examination of possible segregation of disease response within these lines to determine the number of dominant and recessive genes is beyond the scope of the current work. However, the differential reactions observed with the various TuMV isolates examined here should help to identify the number of genes and ultimately to identify new sources of TuMV resistance that could be pyramided to confer more effective, long-lasting resistance against multiple strains.

In summary, we have generated a total of 20 distinct infectious clones of TuMV isolates (including three from prior work; Han et al. 2016) infecting radish. We have demonstrated that there are at least three classes of TuMV isolates causing mild symptoms in $N$. benthamiana among basal-BR strain isolates from radish, whereas the symptoms in Chinese cabbage and radish were not correlated with those in $N$. benthamiana. These results will form the background for further analysis of differences in symptom expression, expanding our knowledge of an important potyvirus and its host interactions, potentially leading to more sustainable resistance to TuMV.

\section{LITERATURE CITED}

Casteel, C. L., Yang, C., Nanduri, A. C., De Jong, H. N., Whitham, S. A., and Jander, G. 2014. The NIa-Pro protein of Turnip mosaic virus improves growth and reproduction of the aphid vector, Myzus persicae (green peach aphid). Plant J. 77:653-663.

Chung, B. Y., Miller, W. A., Atkins, J. F., and Firth, A. E. 2008. An overlapping essential gene in the Potyviridae. Proc. Natl. Acad. Sci. USA 105: 5897-5902.

Chung, J. S., Han, J. Y., Kim, J. K., Ju, H. K., Gong, J. S., Seo, E. Y., Choi, S. R., Lim, Y. P., Hammond, J., and Lim, H. S. 2016. Nationwide survey of Turnip mosaic virus and selection of cabbage lines with resistance against major TuMV isolates. Korean J. Agric. Sci. 43:567-574.

Chung, J. S., Han, J. Y., Kim, J. K., Ju, H. K., Gong, J. S., Seo, E. Y., Hammond, J., and Lim, H. S. 2015. Survey of viruses present in radish fields in 2014. Res. Plant Dis. 21:235-242.

Dallot, S., Quiot-Douine, L., Sáenz, P., Cervera, M. T., Garcia, J. A., and Quiot, J. B. 2001. Identification of Plum pox virus determinants implicated in specific interactions with different Prunus spp. Phytopathology 91: 159-164.
Dougherty, W. G., Carrington, J. C., Cary, S. M., and Parks, T. D. 1988. Biochemical and mutational analysis of a plant virus polyprotein cleavage site. EMBO J. 7:1281-1287.

Fujiwara, A., Inukai, T., Kim, B. M., and Masuta, C. 2011. Combinations of a host resistance gene and the CI gene of turnip mosaic virus differentially regulate symptom expression in Brassica rapa cultivars. Arch. Virol. 156: 1575-1581.

Han, J. Y., Chung, J. S., Kim, J. K., Seo, E. Y., Kilcrease, J. P., Bauchan, G. R., Lim, S. M., Hammond, J., and Lim, H. S. 2016. Comparison of helper component-protease RNA silencing suppression activity, subcellular localization, and aggregation of three Korean isolates of Turnip mosaic virus. Virus Genes 52:592-596.

Jenner, C. E., Sánchez, F., Nettleship, S. B., Foster, G. D., Ponz, F., and Walsh, J. A. 2000. The cylindrical inclusion gene of Turnip mosaic virus encodes a pathogenic determinant to the Brassica resistance gene TuRB01. Mol. Plant-Microbe Interact. 13:1102-1108.

Jenner, C. E., Tomimura, K., Ohshima, K., Hughes, S. L., and Walsh, J. A. 2002. Mutations in Turnip mosaic virus P3 and cylindrical inclusion proteins are separately required to overcome two Brassica napus resistance genes. Virology 300:50-59.

Jenner, C. E., Wang, X., Tomimura, K., Ohshima, K., Ponz, F., and Walsh, J. A. 2003. The dual role of the potyvirus P3 protein of Turnip mosaic virus as a symptom and avirulence determinant in brassicas. Mol. Plant-Microbe Interact. 16:777-784.

Kozubek, E., Irzykowski, W., and Lehmann, P. 2007. Genetic and molecular variability of a Turnip mosaic virus population from horseradish (Cochlearia armoracia L.). J. Appl. Genet. 48:295-306.

Lim, H. S., Bragg, J. N., Ganesan, U., Ruzin, S., Schichnes, D., Lee, M. Y., Vaira, A. M., Ryu, K. H., Hammond, J., and Jackson, A. O. 2009. Subcellular localization of the Barley stripe mosaic virus triple gene block proteins. J. Virol. 83:9432-9448.

Nguyen, H. D., Tomitaka, Y., Ho, S. Y. W., Duchêne, S., Vetten, H. J., Lesemann, D., Walsh, J. A., Gibbs, A. J., and Ohshima, K. 2013b. Turnip mosaic potyvirus probably first spread to Eurasian Brassica crops from wild orchids about 1000 years ago. PLoS One 8:e55336.

Nguyen, H. D., Tran, H. T. N., and Ohshima, K. 2013a. Genetic variation of the Turnip mosaic virus population of Vietnam: A case study of founder, regional, and local influences. Virus Res. 171:138-149.

Ohshima, K., Yamaguchi, Y., Hirota, R., Hamamoto, T., Tomimura, K., Tan, Z., and Chen, J. 2002. Molecular evolution of Turnip mosaic virus: Evidence of host adaption, genetic recombination and geographical spread. J. Gen. Virol. 83:1511-1521.

Olspert, A., Chung, B. Y.-W., Atkins, J. F., Carr, J. P., and Firth, A. E. 2015. Transcriptional slippage in the positive-sense RNA virus family Potyviridae. EMBO Rep. 16:995-1004.

Park, C. H., Ju, H. K., Han, J. Y., Park, J. S., Kim, I. H., Seo, E. Y., Kim, J. K., Hammond, J., and Lim, H. S. 2017. Complete nucleotide sequences and construction of full-length infectious cDNA clones of Cucumber green mottle mosaic virus (CGMMV) in a versatile newly developed binary vector including both $35 \mathrm{~S}$ and $\mathrm{T} 7$ promoters. Virus Genes 53: 286-299.

Revers, F., and Garcia, J. A. 2015. Molecular biology of potyviruses. Adv. Virus Res. 92:101-199.

Rodamilans, B., Valli, A., Mingot, A., San Leon, D., Baulcombe, D., López-Moya, J. J., and Garcia, J. A. 2015. RNA polymerase slippage as a mechanism for the production of frameshift gene products in plant viruses of the Potyviridae family. J. Virol. 89:6965-6967.

Rojas, M. R., Zerbini, F. M., Allison, R. F., Gilbertson, R. L., and Lucas, W. J. 1997. Capsid protein and helper component-proteinase function as potyvirus cell-to-cell movement proteins. Virology 237:283-295.

Salvador, B., Delgadillo, M. O., Sáenz, P., Garcia, J. A., and Simon-Mateo, C. 2008. Identification of Plum pox virus pathogenicity determinants in herbaceous and woody hosts. Mol. Plant-Microbe Interact. 21:20-29.

Sáenz, P., Cervera, M. T., Dallot, S., Quiot, L., Quiot, J. B., Riechmann, J. L., Garcia, J. A. 2000. Identification of a pathogenicity determinant of Plum pox virus in the sequence encoding the $\mathrm{C}$-terminal region of protein $\mathrm{P} 3+$ 6K1. J. Gen. Virol. 81:557-566.

Sánchez, F., Wang, X., Jenner, C. E., Walsh, J. A., and Ponz, F. 2003. Strains of Turnip mosaic potyvirus as defined by the molecular analysis of the coat protein gene of the virus. Virus Res. 94:33-43.

Shi, M. L., Li, H. Y., Schubert, J., and Zhou, X. P. 2007. Sequence analysis of $\mathrm{CP}$ and HC-Pro genes of Turnip mosaic virus isolates from China. Acta Virol. 52:59-62.

Shukla, D. D., Ward, C. W., and Brunt, A. A. 1994. The Potyviridae. CAB International, Wallingford, UK.

Simón-Buela, L., Guo, H. S., and García, J. A. 1997. Long sequences in the 5' noncoding region of plum pox virus are not necessary for viral infectivity but contribute to viral competitiveness and pathogenesis. Virology 233: 157-162. 
Suehiro, N., Natsuake, T., Watanabe, T., and Okuda, S. 2004. An important determinant of the ability of Turnip mosaic virus to infect Brassica spp. and/or Raphanus sativus is in its P3 protein. J. Gen. Virol. 85:2087-2098.

Tan, Z., Gibbs, A. J., Tomataka, Y., Sanchez, F., Ponz, F., and Ohshima, K. 2005. Mutations in Turnip mosaic virus genomes that have adapted to Raphanus sativus. J. Gen. Virol. 86:501-510.

Tan, Z., Wada, Y., Chen, J., and Ohshima, K. 2004. Inter- and intralineage recombinants are common in natural populations of Turnip mosaic virus. J. Gen. Virol. 85:2683-2696.

Tomimura, K., Gibbs, A. J., Jenner, C. E., Walsh, J. A., and Ohshima, K. 2003. The phylogeny of Turnip mosaic virus; comparisons of 38 genomic sequences reveal a Eurasian origin and a recent 'emergence' in east Asia. Mol. Ecol. 12:2099-2111.

Tomitaka, Y., and Ohshima, K. 2006. A phylogeographical study of the Turnip mosaic virus population in East Asia reveals an 'emergent' lineage in Japan. Mol. Ecol. 15:4437-4457.

Tomlinson, J. A. 1987. Epidemiology and control of virus diseases of vegetables. Ann. Appl. Biol. 110:661-681.

Urcuqui-Inchima, S., Haenni, A. L., and Bernardi, F. 2001. Potyvirus proteins: A wealth of functions. Virus Res. 74:157-175.
Vijayapalani, P., Maeshima, M., Nagasaki-Takekuchi, N., and Miller, W. A. 2012. Interactions of the trans-frame potyvirus protein P3N-PIPO with host protein PCaP1 facilitates potyvirus movement. PLoS Pathog 8:e1002639.

Walsh, J. A. 1989. Genetic control of immunity to turnip mosaic virus in winter oilseed rape (Brassica napus ssp. oleifera) and the effect of foreign isolates of the virus. Ann. Appl. Biol. 115:89-99.

Walsh, J. A., and Jenner, C. E. 2002. Turnip mosaic virus and the quest for durable resistance. Mol. Plant Pathol. 3:289-300.

Walsh, J. A., Rusholme, R. L., Hughes, S. L., Jenner, C. E., Bambridge, J. M., Lydiate, D. J., and Green, S. K. 2002. Different classes of resistance to turnip mosaic virus in Brassica rapa. Eur. J. Plant Pathol. 108:15-20.

Wang, H. Y., Liu, J. L., Gao, R., Chen, J., Shao, Y. H., and Li, X. D. 2009. Complete genomic sequence analysis of Turnip mosaic virus basal-BR isolates from China. Virus Genes 38:421-428.

White, K. A. 2015. The polymerase slips and PIPO exists. EMBO Rep. 16: 885-886.

Zubareva, I., Vinogradova, S., Gribova, T., Monakhos, S., Skryabin, K., and Ignatov, A. 2013. Genetic diversity of Turnip mosaic virus and the mechanism of its transmission by Brassica seeds. Dokl. Biochem. Biophys. 450: $119-122$ 